Tropical Journal of Pharmaceutical Research April 2020; 19 (4): 789-796

ISSN: $1596-5996$ (print); 1596-9827 (electronic)

(C) Pharmacotherapy Group, Faculty of Pharmacy, University of Benin, Benin City, 300001 Nigeria.

\title{
Autophagy inhibition by chloroquine prevents increase in blood pressure and preserves endothelial functions
}

\author{
Moon Jain ${ }^{1,2}$, Hina Iqbal ${ }^{3}$, Pankaj Yadav ${ }^{3}$, Himalaya Singh ${ }^{1,2}$, Debabrata \\ Chanda $^{3}$, Kumaravelu Jagavelu ${ }^{1,2}$, Kashif Hanif ${ }^{1,2 *}$ \\ ${ }^{1}$ Division of Pharmacology, Council of Scientific and Industrial Research-Central Drug Research Institute, Lucknow 226031, \\ India, ${ }^{2}$ Academy of Scientific and Innovative Research, Ghaziabad, UP, India, ${ }^{3}$ Molecular Bioprospection Department, Council \\ of Scientific and Industrial Research-Central Institute of Medicinal and Aromatic Plants, Lucknow 226015, India
}

*For correspondence: Email: k_hanif@cdri.res.in; Tel: +91-522-2772550

Sent for review: 31 October 2019

Revised accepted: 28 January 2020

\begin{abstract}
Purpose: To determine the effects of lysosomal inhibition of autophagy by chloroquine (CHQ) on hypertension-associated changes in the endothelial functions.

Method: Angiotensin II (Ang II)-treated human endothelial cell line EA.hy926 and renovascular hypertensive rats were subjected to $\mathrm{CHQ}$ treatment (in vitro: $0.5,1$, and $2.5 \mu \mathrm{M}$; in vivo: $50 \mathrm{mg} / \mathrm{kg} /$ day for three weeks). Changes in the protein expressions of LC3b II (autophagosome formation marker) and p62 (autophagy flux marker) were assessed using immunoblotting. Cell migration assay, tubule formation assay (in vitro), and organ bath studies (in vivo) were performed to evaluate the endothelial functions. Hemodynamic parameters were measured as well.

Results: A higher expression of LC3b II and a reduced expression of p62 observed in the Ang II-treated endothelial cells, as well as in the aorta of the hypertensive rats, indicated enhanced autophagy. Treatment with CHQ resulted in reduced autophagy flux (in vitro as well as in vivo) and suppressed Ang Il-induced endothelial cell migration and angiogenesis (in vitro). The treatment with CHQ was also observed to prevent increase in blood pressure in hypertensive rats and preserved acetylcholineinduced relaxation in phenylephrine-contracted aorta from the hypertensive rats. In addition, chloroquine attenuated Ang II-induced contractions in the aorta of normotensive as well as hypertensive rats.

Conclusion: These observations indicated that $\mathrm{CHQ}$ lowers the blood pressure and preserves the vascular endothelial function during hypertension.
\end{abstract}

Keywords: Angiotensin II, Autophagy, Chloroquine, Endothelial function, Hypertension, Vascular dysfunction

\begin{abstract}
This is an Open Access article that uses a fund-ing model which does not charge readers or their institutions for access and distributed under the terms of the Creative Commons Attribution License (http://creativecommons.org/licenses/by/4.0) and the Budapest Open Access Initiative (http://www.budapestopenaccessinitiative.org/read), which permit unrestricted use, distribution, and reproduction in any medium, provided the original work is properly credited.

Tropical Journal of Pharmaceutical Research is indexed by Science Citation Index (SciSearch), Scopus, International Pharmaceutical Abstract, Chemical Abstracts, Embase, Index Copernicus, EBSCO, African Index Medicus, JournalSeek, Journal Citation Reports/Science Edition, Directory of Open Access Journals (DOAJ), African Journal Online, Bioline International, Open-J-Gate and Pharmacy Abstracts
\end{abstract}

\section{INTRODUCTION}

Autophagy is a regulated cellular process in which damaged proteins and cell organelles are recycled after their sequestration into autophagolysosomes (bi-membranous intracellu- lar vesicles) followed by lysosome-dependent degradation [1]. The upregulation of autophagy in cells is characterized by increased autophagosome formation and increased autophagic flux (marked by increased LC3B-II 
expression and a decreased p62 expression), and manifests early signs of stress [2].

Enhanced autophagy exerts a detrimental effect during various cardiovascular pathologies, such as severe mitral and tricuspid regurgitation, pressure overload-induced cardiac remodeling, heart failure, atherosclerosis [3], and pulmonary hypertension [4]. Enhanced autophagy is also linked to the progression of renovascular hypertension-associated cardiac remodeling [5]. Angiotensin II (Ang II) plays a crucial role in the pathophysiology of hypertension and has been reported to induce endothelial cell autophagy [6]. Modulation of autophagy in bovine aortic endothelial cells has been demonstrated to alter the endothelial functions. Genetic stimulation of autophagy the overexpression of ATG5 has been observed to increase endothelial cell migration and angiogenesis, while reduced autophagy inhibits endothelial cell migration as well as angiogenesis [7].

The endothelium is a prime target for damage during hypertension. However, limited information is available regarding the role of vascular autophagy in endothelial dysfunction occurring during hypertension. This formed the basis for encouraging the present study. Lysosomal inhibitors of autophagy, such as $\mathrm{CHQ}$ and bafilomycin, have been used extensively for the study of autophagy inhibition in various pathologies, including cancer [8] and cardiac hypertrophy [9].

Therefore, the present study was aimed to determine the effects of $\mathrm{CHQ}$-induced lysosomal inhibition of autophagy on the endothelial functions as a response to Ang II-treatment in vitro and in the rat model for renovascular hypertension.

\section{EXPERIMENTAL}

\section{In vitro cell culture}

Human endothelial cell line EA.hy926 [originally developed by $\mathrm{C}$. J. Edgell, and provided as a gift from the University of North Carolina (UNC) Lineberger Comprehensive Cancer Center, USA] was used for conducting the in vitro experiments. The cells were cultured in complete Dulbecco's Modified Eagle Medium (DMEM; HiMedia, India) enriched with $10 \%$ fetal bovine serum (FBS; HiMedia, India) and $1 \%$ penicillin/streptomycin (HiMedia, India), at $37{ }^{\circ} \mathrm{C}$ in $5 \% \mathrm{CO}_{2}$ atmosphere, until 80 - $90 \%$ confluence was attained. After that, the cells were selected randomly and subjected to the respective treatments in each test.

\section{Cell viability assay}

In order to determine the non-cytotoxic concentration of $\mathrm{CHQ}$ for the human endothelial cell line EA.hy926, the effect of $\mathrm{CHQ}$ on the cell viability was determined using the MTT assay. This assay is based on the metabolic reduction of 3-[4,5-dimethylthiazol-2-y]-2,5-diphenyltetrazolium bromide (MTT). The cells from the cell line EA.hy926 were seeded $\left(2 \times 10^{4}\right.$ cells per well) in the wells of 96-well plates and left undisturbed overnight to allow adherence. Subsequently, the cells in the wells were randomly exposed to various concentrations of CHQ $(0.5-10 \mu \mathrm{M})$ for $24 \mathrm{~h}$, followed by incubation with MTT at a final concentration of $0.5 \mathrm{mg} / \mathrm{L}$ for 2-3 $\mathrm{h}$. After the incubation and the removal of media, dimethyl sodium sulfoxide $(150 \mu \mathrm{L})$ was added, and the changes in the absorbance at $570 \mathrm{~nm}$ were recorded using a microplate reader (BioTek, USA). Data were normalized to the respective controls, and are presented as percentage cell viability.

\section{Endothelial cell migration assay}

The effect of $\mathrm{CHQ}$ co-treatment on the Ang IIinduced migration of the human endothelial cell line was studied using the in vitro wound closure assay. The cell line cultured in 6-well plates and having reached $80 \%-90 \%$ confluence was mechanically scratched using a sterile pipette tip to create a cell-free zone. The debris was removed through washing with phosphatebuffered saline (PBS). The culture medium containing $2.5 \%$ FBS was added for wound healing.

Subsequently, the cells were randomly assigned and subjected to different treatments: control (untreated) and the Ang II $(1 \mu \mathrm{M})$ with or without co-exposure to $\mathrm{CHQ}(0.5 \mu \mathrm{M}$, provided $1 / 2 \mathrm{~h}$ before the Ang II treatment) treatment. After the treatments, phase-contrast images of the scratched area were captured at different time points (0 $\mathrm{min}, 12 \mathrm{~h}$, and $24 \mathrm{~h}$ ). The image captured just after the addition of Ang II was considered the image at $0 \mathrm{~min}$ time point. The obtained images were analyzed using the Image $\mathrm{J}$ software version $1.46 \mathrm{r}$ (released by Wayne Rasband, National Institute of Health, USA).

\section{Endothelial capillary tube formation assay in Matrigel}

The effect of co-treatment with $\mathrm{CHQ}$ (0.5 and 1 $\mu \mathrm{M})$ on the Ang II ( $1 \mu \mathrm{M})$-induced angiogenesis was studied using the endothelial capillary tube formation assay [10]. 


\section{Animals}

All the experiments were conducted in accordance with the International Ethical Standards, with prior approval obtained from the Institutional Animal Ethics Committee (IAEC) of CSIR-Central Drug Research Institute (CSIRCDRI, approval no. IAEC/2017/281). All the animals were handled with care, in accordance with the guidelines provided by National Research Council (USA) [11]. All animals were treated in accordance with Canadian Council on Animal Care (CCAC) guidelines [12]. Male Sprague-Dawley (SD) rats, each weighing 180 $200 \mathrm{~g}$, were procured from the National Laboratory Animal Center (NLAC), CSIR-CDRI, Lucknow, India, and were housed in polypropylene cages. The rats were maintained under standard environmental conditions comprising 12-h photoperiod, $23 \pm 2{ }^{\circ} \mathrm{C}$ temperature, and 60\%-65\% humidity. Feed (dry pellets) and water were available ad libitum.

\section{Renovascular model of hypertension}

The male SD rat is a widely accepted animal model for renovascular hypertension. The model was developed through partial ligation of the renal artery according to a previously published procedure $[13,14]$. The rats developed significant hypertension within five weeks. Two weeks after the surgery, the animals were assigned randomly into 3 groups with 5 animals each $(n=5)$ : shamoperated control (Sham), renovascular hypertensive rats (HTN), and $\mathrm{CHQ}$-treated hypertensive rats $(\mathrm{HTN}+\mathrm{CHQ} ; 50 \mathrm{mg} / \mathrm{kg}$ ); and the aorta from all groups were subjected to immunoblotting and organ-bath experiments. The $\mathrm{HTN}+\mathrm{CHQ}$ group received daily drug treatment beginning from the $3^{\text {rd }}$ week until the end of the $5^{\text {th }}$-week post-surgery.

\section{Measurement of arterial blood pressure and heart rate in anesthetized rats}

Upon completion of the treatment schedule, the rats from each group were anesthetized with urethane (1.25 g/kg; i.p.). The hemodynamic parameters, namely, systolic blood pressure (SBP), diastolic blood pressure (DBP), mean arterial blood pressure (MAP), and heart rate $(\mathrm{H})$, were recorded by following a previously published invasive method [10].

\section{Immunoblotting}

Cell- or tissue-lysates were fractionated on a 12 $\%$ SDS-PAGE gel, followed by transfer to a polyvinylidene fluoride membrane. Subsequently, the blots were blocked using $5 \%$ bovine serum albumin (BSA) prepared in Tris-buffered saline (TBS) containing $0.1 \%$ Tween 20 , and incubated overnight with diluted antibodies- anti-p62 (1:1000 dilution; Sigma, USA), anti-LC3B (1:1000 dilution; Cell signaling technology), and anti-beta actin (1:10000 dilution; Sigma, USA). After incubation with the respective antibodies, the membranes were incubated for another $2 \mathrm{~h}$ with the respective HP-conjugated mouse or rabbit secondary antibodies, following which they were visualized using ECL western blotting detection reagent. Immunoblot intensity was analyzed using mylmageAnalysis software version 2.0 (Thermo Scientific, USA).

\section{Rat aortic rings preparation and tension recording}

Soon after the measurement of the hemodynamic parameters, the descending thoracic aorta was isolated, placed in ice-cold Modified Kreb's Henseleit solution (MKHS) [composition (in mM): $\mathrm{NaCl}, 118 ; \mathrm{NaHCO}_{3}, 24$; $\mathrm{KCl}, 4 ; \mathrm{CaCl}_{2}, 1.8 ; \mathrm{MgSO}_{4}, 1 ; \mathrm{NaH}_{2} \mathrm{PO}_{4}, 0.43$; and glucose, 5.56; $\mathrm{pH} 7.4]$, and the adherent adipose and connective tissues were cautiously trimmed off. The transversely cut, $2-3-\mathrm{mm}$ wide aortic rings were mounted individually in a twochambered organ bath (ADInstruments, Australia) containing MKHS, maintained thermostatically at $37{ }^{\circ} \mathrm{C}$ and aerated continuously with carbogen gas. The arterial rings were subjected to passive tension for 60 min, and the tension experiments were conducted using the methods described in a previously published report [15].

\section{Statistical analysis}

The data were collected in a blinded manner, and the results were expressed as mean \pm standard error of the mean (SEM). One-way ANOVA, followed by post-hoc analysis with Bonferroni's test, was used for determining significant differences among treatment groups. All the statistical analyses were performed in the GraphPad Prism software version 5.00.28 (GraphPad Software, Inc., San Diego, CA, USA). A probability value of $<0.05$ was considered statistically significant.

\section{RESULTS}

\section{Chloroquine inhibits angiotensin II-induced upregulation of autophagy in human endothelial cell line, EA.hy926}

After $24 \mathrm{~h}$ of exposure to $\mathrm{CHQ}$, it was observed that the $\mathrm{CHQ}$ concentrations of $0.5,1$, and 2.5 $\mu \mathrm{M}$ were not toxic for the human endothelial cell 
line EA.hy926 (Figure 1 a). Loss of cell viability was observed with the $\mathrm{CHQ}$ concentrations of 5 and $10 \mu \mathrm{M}$. Therefore, the $\mathrm{CHQ}$ concentrations of $0.5,1$, and $2.5 \mu \mathrm{M}$ were used for further experiments. Treatment of the human endothelial cell line EA.hy926 with Ang II $(1 \mu \mathrm{M})$ for $24 \mathrm{~h}$ was observed to enhance the expression of the LC3II/LC3-I protein (Figure $1 \mathrm{~b}$ ) and reduce the expression of p62, indicating an increase in the autophagosome formation and the flux of autophagy, respectively.

Co-treatment with $\mathrm{CHQ}(0.5-2.5 \mu \mathrm{M})$ did not result in reduction in the LC3-II/LC3-I protein ratio that was increased by Ang II, rather $\mathrm{CHQ}$ at a concentration of $2.5 \mu \mathrm{M}$ was observed to increase this ratio, demonstrating that the Ang IIinduced autophagosome formation remained unaffected by the $\mathrm{CHQ}$ co-treatment (at $0.5 \mu \mathrm{M}$ concentration). However, the $\mathrm{CHQ}$ co-treatment was observed to significantly increase the expression of $\mathrm{p} 62$ in the Ang II-treated endothelial cells in a concentration-dependent manner $(0.5-2.5 \mu \mathrm{M})$, indicating the suppression of Ang II-induced autophagy flux owing to the inhibition of lysosomal function.

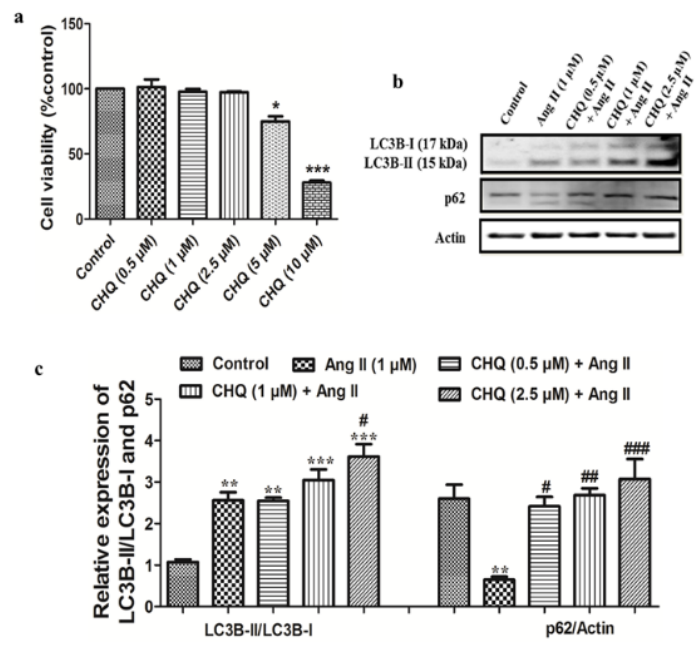

Figure 1: Effect of $\mathrm{CHQ}$ exposure for $24 \mathrm{~h}$ on (a) the cell viability of human endothelial cell line EA.hy926, and (b and $\mathbf{c}$ ) on the Ang II $(1 \mu \mathrm{M})$-induced LC3B-II and Ang II $(1 \mu \mathrm{M})$-reduced p62 expression in the human endothelial cell line EA.hy926. ${ }^{*} p<0.05,{ }^{* *} p<$ 0.01 , and ${ }^{* * *} p<0.005$ vs. control; ${ }^{\#} p<0.05$, ${ }^{\#} p<0.01$, and ${ }^{\# \#} p<0.005$ vs. Ang II-treated Ea.hy926 cells ( $\mathrm{n}=$ 5)

\section{Chloroquine inhibits angiotensin II-induced endothelial cell migration and angiogenesis}

Ang II $(1 \mu \mathrm{M})$ treatment for $12 \mathrm{~h}$, as well as for 24 $\mathrm{h}$, was observed to significantly induce endothelial cell migration (Figure 2 a) and angiogenesis (marked by increased tubule formation; Figure 2 b) in the human endothelial cell line EA.hy926. Co-treatment with $\mathrm{CHQ}$ at autophagy-inhibiting concentrations (0.5 and 1 $\mu \mathrm{M})$ significantly suppressed the Ang II-induced endothelial cell migration at $12 \mathrm{~h}$ and $24 \mathrm{~h}$. However, $\mathrm{CHQ}$ per se $(1 \mu \mathrm{M})$ exerted an effect on endothelial cell migration. In addition, $\mathrm{CHQ}$ treatment (at 0.5 and $1 \mu \mathrm{M}$ concentrations) significantly suppressed both basal and Ang IIinduced tubule formation in endothelial cells.

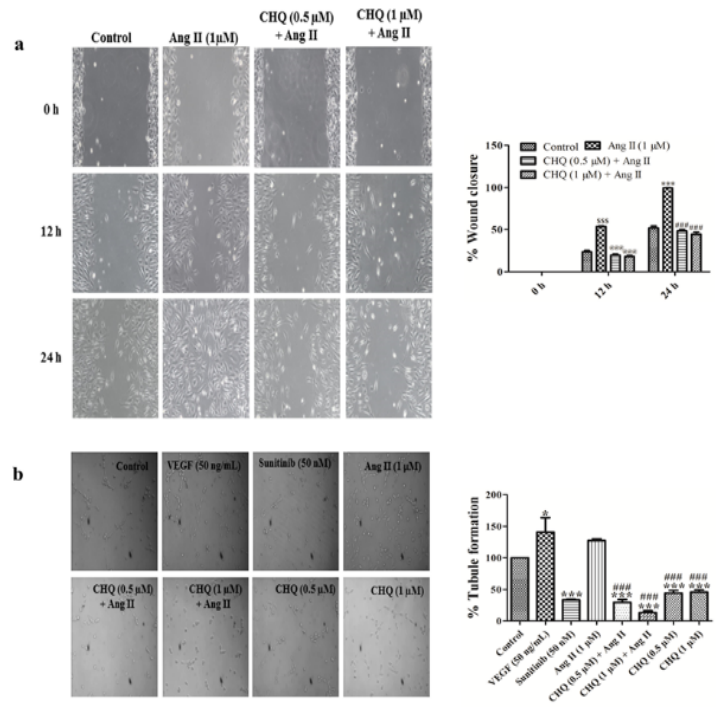

Figure 2: Effect of CHQ on Ang II (1 $\mu \mathrm{M})$-induced: (a) cell migration and (b) capillary tubule formation in human endothelial cell line EA.hy926; $\$ \$ p<0.005$ vs. Control $(12 \mathrm{~h}) ;{ }^{*} p<0.05$ and ${ }^{* * *} p<0.005$ vs. control

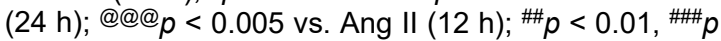
$<0.005$ vs. Ang II (24 h)-treated Ea.hy926 cells $(n=5)$

Chloroquine prevents a rise in blood pressure in rat model for renovascular hypertension

After the partial ligation of the renal artery, the rats became hypertensive within five weeks after surgery. A significant rise (Figure 3 ) in the parameters of SBP $(150.00 \pm 1.3 \mathrm{mmHg})$, DBP $(94.1 \pm 3.8 \mathrm{mmHg}), \operatorname{MAP}(112.7 \pm 2.7 \mathrm{mmHg})$, and $\mathrm{H}(407.7 \pm 12.8 \mathrm{bpm})$ was observed compared to the Sham (SBP: $106.9 \pm 3.5 \mathrm{mmHg}$; DBP: $68.7 \pm 4.3 \mathrm{mmHg}$; MAP: $81.4 \pm 3.0 \mathrm{mmHg}$; and $\mathrm{H}: 339.1 \pm 13.4 \mathrm{bpm})$. Normalization of these alterations in the hemodynamic parameters was achieved when the renovascular hypertensive rats were treated with $\mathrm{CHQ}$ (po, $50 \mathrm{mg} / \mathrm{kg}$ ) for the duration between the third and the $5^{\text {th }}$ week post-surgery (SBP: $110.4 \pm 4.7 \mathrm{mmHg}$; DBP: $78.6 \pm 3.7 \mathrm{mmHg}$; MAP: $90.9 \pm 3.5 \mathrm{mmHg}$, and $\mathrm{H}: 296.9 \pm 9.1 \mathrm{bpm})$. 

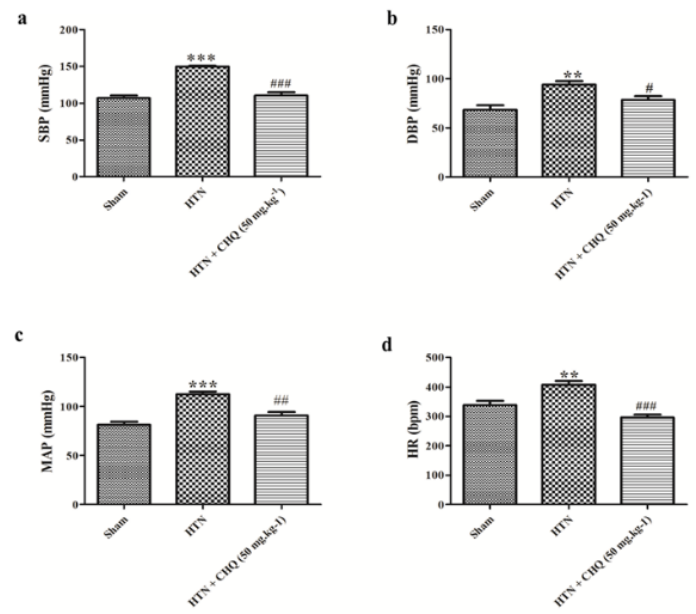

Figure 3: Elevation effect of $\mathrm{CHQ}$ on blood pressure in the rat model of renovascular hypertension. (a) Systolic blood pressure (SBP), (b) diastolic blood pressure (DBP), c) mean arterial pressure (MAP), and d) heart rate $(\mathrm{H}) ;{ }^{* * *} p<0.005,{ }^{* *} p<0.01$ vs. sham; ${ }^{\# \#} p$ $<0.005,{ }^{\#} p<0.01$, and ${ }^{\#} p<0.05$ vs. renovascular hypertensive group $(n=5)$

\section{Chloroquine inhibits hypertension-induced vascular autophagy}

Vascular autophagy was observed to be upregulated in the aorta of the renovascular hypertensive rats compared to the Sham and was characterized by a significant increase in the LC3-II/LC3-I expression and decrease in the p62 expression (Figure 4). CHQ treatment for three weeks was observed to significantly suppress the effect of hypertension on the LC3-II/LC3-I and p62 expressions in the aortic tissue.
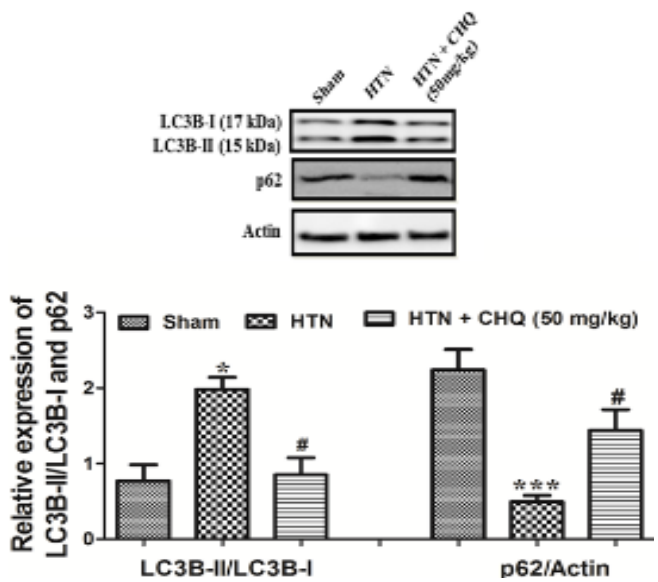

Figure 4: Effect of $\mathrm{CHQ}$ treatment on the relative expressions of the markers of autophagy (LC3B-II and p62) in the aorta of renovascular hypertensive rats; ${ }^{* * *} p$

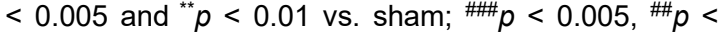
0.01 , and ${ }^{\#} p<0.05$ vs. renovascular hypertensive group $(n=5)$

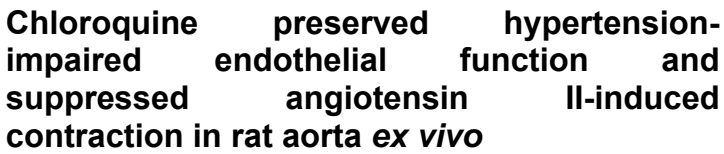

A significant reduction was observed in the acetylcholine-induced relaxation of the PEcontracted aortic rings of the HTN rats, indicating the functional impairment of endothelium. Chloroquine treatment was observed to preserve the endothelial functions in the hypertensive rats (Figure $5 \mathrm{a}, \mathrm{b}, \mathrm{c}$, and d). A significant reduction in the aortic tone, induced through a single exposure to Ang II $(1 \mu \mathrm{M})$, was observed in the aorta from the Sham or the HTN rats treated with $\mathrm{CHQ}$ ex vivo $(100 \mu \mathrm{M})$ as well as in the aorta of the CHQ-treated HTN rats $(50 \mathrm{mg} / \mathrm{kg} /$ day for three weeks; Figure $5 \mathrm{e}, \mathrm{f}, \mathrm{g}, \mathrm{h}, \mathrm{i}$, and j).

Endothelial function

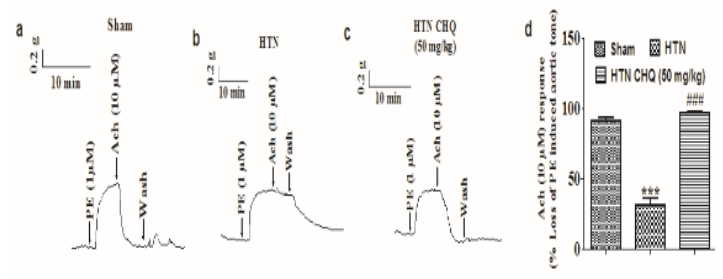

Ang 11 (1 $\mu$ M) induced aortic contractions
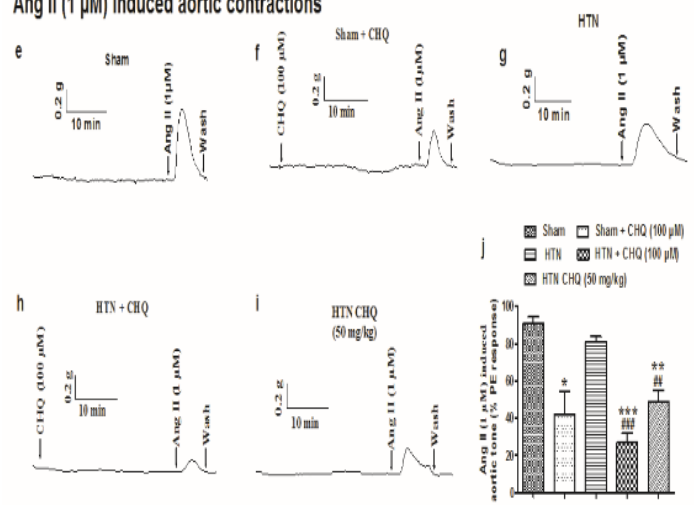

Figure 5: Effect of $\mathrm{CHQ}$ on endothelial function impaired because of hypertension (a, b, c, and d), and on Ang II-induced contraction in rat aorta ex vivo (e, $\mathbf{f}$, g, h, i, and j). ${ }^{* * *} P<0.005,{ }^{* *} p<0.001$, and ${ }^{*} p<0.05$ vs. sham; ${ }^{\# \#} p<0.005,{ }^{\# \#} p<0.001$ vs. renovascular hypertensive group

\section{DISCUSSION}

The present work investigated the effect of CHQinduced lysosomal inhibition of autophagy on the hypertension-associated endothelial dysfunction. The results obtained in the present investigation demonstrated that autophagy has an important role in Ang II-induced endothelial cell migration and angiogenesis, and its inhibition by $\mathrm{CHQ}$ provides endothelial protection during hypertension. 
Autophagy is a key process in the integrated response to cellular stress and is initiated in the vascular cells of the diseased arteries, including the endothelial cells [2]. In the present work, an increase in autophagy was observed in the endothelial cells upon the Ang II exposure, which was characterized by enhanced LC3-II/LC3-I (autophagosome formation marker) expression and reduced p62 (autophagic flux marker) expression. The Ang II-induced autophagy flux was significantly suppressed upon co-treatment with $\mathrm{CHQ}$, evidenced by the enhanced p62 expression. On the other hand, the effect of Ang II on autophagosome formation remained unaffected upon the $\mathrm{CHQ}$ co-treatment, as evidenced by the unaltered Ang II-induced expression of the LC3-II/LC3-I protein in the CHQ-co-treated endothelial cells. These results indicated a late-stage blockage of the autophagy cascade by $\mathrm{CHQ}$. This was consistent with the fact that lysosomotropic agents such as $\mathrm{CHQ}$ and bafilomycin block autophagy at its maturation phase by interrupting the fusion of autophagosome with lysosome to form autophagolysosome, while the initial phases of autophagy remain unaffected by these agents [16].

Autophagy has been reported to play a pivotal role in regulating cell migration by directing the focal adhesion turnover and the tensional homeostasis, owing to its fundamental characteristic of compartmentalizing and degrading the cellular constituents $[17,18]$. In the present work, CHQ significantly suppressed the Ang II-induced endothelial cell migration, which suggested the involvement of autophagy therein. Chloroquine also inhibited both basal and Ang IIinduced angiogenesis, which was marked by reduced tubule formation in the endothelial cells. This corroborated the finding of a previous study, that enhanced autophagy increases angiogenesis, while autophagy inhibition suppresses the angiogenesis without affecting the expression of the pro-angiogenic factors such as the vascular endothelial growth factor, platelet-derived growth factor, or integrin $\alpha \mathrm{V}$ [7]. It is known that the endothelial cells involved in neovasculogenesis play a crucial role in the pathophysiology of various cardiovascular complications, such as atherosclerosis, aortic aneurysm, stroke, and peripheral vascular diseases [19]. In this context, the results of the present work demonstrated that the enhanced endothelial cell autophagy could be of pathological significance during hypertension. In the present study, prolonged treatment with $\mathrm{CHQ}$ prevented the increase in the blood pressure in the renovascular hypertensive rats, which corroborated with a recent study that reported inhibition of hypertension with the use of $\mathrm{CHQ}$ in spontaneously hypertensive rats [20]. Confirming the findings of the in vitro investigations conducted in the present study, CHQ also inhibited the upregulation in the vascular autophagy flux in the aorta of the renovascular hypertensive rats, which represent a RAASdependent model of hypertension. In contrast, prolonged $\mathrm{CHQ}$ treatment suppressed the Ang IIinduced autophagosome formation in the aorta of the hypertensive rats, which could be attributed to the reduction in the hemodynamic shear stress [21-23].

Impairment of vasoreactivity is an integral characteristic of hypertension, which also accounts for the increased vascular stress occurring during hypertension [24]. In the present study, sustained inhibition of autophagy by $\mathrm{CHQ}$ prevented the hypertension-induced endothelial dysfunction, as evidenced by improvement in the acetylcholine-induced relaxation in the aorta of the CHQ-treated renovascular hypertensive rats. In addition, the chloroquine treatment (ex vivo as well as in vivo) inhibited the contractions induced by Ang II in the aorta of normotensive as well as hypertensive rats.

Taken together, the findings of the present study demonstrate the therapeutic potential of $\mathrm{CHQ}$ induced lysosomal inhibition of autophagy in hypertension-related vascular pathology and the associated complications. Although Ang II was employed as the effector peptide of RAAS throughout the present study, further investigation is required for deciphering the mechanism underlying the interaction between RAAS and vascular autophagy.

\section{CONCLUSION}

The findings of the present study demonstrate that both Ang II and elevated blood pressure, the prime factors governing the vasopathological changes occurring during hypertension, can induce endothelial cell autophagy. Preservation of the endothelial cell functions through lysosomal inhibition of autophagy in Ang IItreated cells or in hypertensive rats highlights its pathological implications in hypertensive vascular disease. In addition, CHQ treatment suppresses the development of hypertension in renovascular hypertensive rats. Thus, autophagy plays an important role in regulating endothelial functions during hypertension, and hence, autophagy inhibition using lysosomotropic agents such as $\mathrm{CHQ}$ protects against hypertension-induced endothelial dysfunction. 


\section{DECLARATIONS}

\section{Acknowledgement}

This work was supported by grants from CSIRCDRI Network project, THUNDER (no. BSC0102), UNDO (no. BSC0103) and Senior Research Fellowship for Moon Jain from Council of Scientific and Industrial Research, Government of India and Ramalingaswami Fellowship to Kumaravelu Jagavelu from Department of Biotechnology, Government of India and University Grants Commission Senior Research Fellowship to Hina lqbal and Himalaya Singh, Department of Biotechnology Senior Research Fellowship to Pankaj Yadav. The authors acknowledge Dr AL Vishwakarma and Madhu Chaturvedi for assisting with flow cytometry. This manuscript is allotted CDRI communication no. 10018.

\section{Conflict of interest}

No conflict of interest is associated with this work.

\section{Contribution of authors}

We declare that this work was done by the authors named in this article, and all liabilities pertaining to claims relating to the content of this article will be borne by the authors. Moon Jain designed, performed experiments, compiled results, and wrote the manuscript. Hina Iqbal, Pankaj Yadav and Debabrata Chanda conducted the vasoreactivity experiments. Himalaya Singh and Kumaravelu Jagavelu did angiogenesis experiments. Kashif Hanif designed the study, analysed the results and wrote the manuscript.

\section{Open Access}

This is an Open Access article that uses a funding model which does not charge readers or their institutions for access and distributed under the terms of the Creative Commons Attribution License (http://creativecommons.org/licenses/by/ 4.0) and the Budapest Open Access Initiative (http://www.budapestopenaccessinitiative.org/rea d), which permit unrestricted use, distribution, and reproduction in any medium, provided the original work is properly credited.

\section{REFERENCES}

1. He C, Klionsky DJ. Regulation mechanisms and signaling pathways of autophagy. Annu Rev Genet 2009; 43: 6793.
2. Ryter SW, Choi AMK. Autophagy: An Integral Component of the Mammalian Stress Response. J Biochem Pharmacol Res 2013; 1(3):1 76-188.

3. Peng N, Meng N, Wang S, Zhao F, Zhao J, Su L, Zhang $S$, Zhang $Y$, Zhao B, Miao J. An activator of mTOR inhibits oxLDL-induced autophagy and apoptosis in vascular endothelial cells and restricts atherosclerosis in apolipoprotein E(-/-) mice. Sci Rep 2014; 4: 5519-5519.

4. Long L, Yang $X$, Southwood M, Lu J, Marciniak SJ, Dunmore BJ, Morrell NW. Chloroquine Prevents Progression of Experimental Pulmonary Hypertension via Inhibition of Autophagy and Lysosomal Bone Morphogenetic Protein Type II Receptor Degradation. Circ Res 2013; 112(8): 1159-1170.

5. Zhang $X$, Gibson ME, Li Z-L, Zhu $X-Y$, Jordan $K L$, Lerman A, Lerman LO. Autophagy Portends the Level of Cardiac Hypertrophy in Experimental Hypertensive Swine Model. Am J Hypertens 2016; 29(1): 81-89.

6. Shan $H$, Guo $D$, Li $X$, Zhao $X$, Li $W$, Bai $X$. From autophagy to senescence and apoptosis in Angiotensin II-treated vascular endothelial cells. APMIS 2014; 122(10): 985-992.

7. Du J, Teng R-J, Guan T, Eis A, Kaul S, Konduri GG, Shi $Y$. Role of autophagy in angiogenesis in aortic endothelial cells. Am J Physiol Cell Physiol 2012; 302(2): C383-C391.

8. Maes $H$, Kuchnio $A$, Carmeliet $P$, Agostinis $P$. Chloroquine anticancer activity is mediated by autophagy-independent effects on the tumor vasculature. Mol Cell Oncol 2016; 3(1): e970097e970097.

9. Chi RF, Wang JP, Wang $K$, Zhang $X L$, Zhang YA, Kang $Y M$, Han $X B$, Li B, Qin FZ, Fan BA. Progressive reduction in myocyte autophagy after myocardial infarction in rabbits: association with oxidative stress and left ventricular remodeling. Cell Physiol Biochem 2017; 44(6): 2439-2454.

10. Jain M, Bhosale V, Tripathi D, Singh H, Pal N, Hanif K, Jagavelu K. Antihypertensive Drugs Aliskiren, Nebivolol, and Olmesartan Reduce Hypertension by Reducing Endothelial Microparticles and Regulating Angiogenesis. J Cardiovasc Pharmacol 2017; 70(3): 176-183.

11. National Research Council. Guide for the care and use of laboratory animals. National Academies Press; 8th Ed. 2010 Dec 27.

12. CCAC. The Guide to the Care and Use of Experimental Animals: Canadian Council of Animal Care; 1993 [cited 2020 Mar 15]. Available from: https://www.ccac.ca/en/standards/guidelines/

13. Kharin SN, Krandycheva VV. Method of Experimental Constriction of Renal Artery for Modeling of Renovascular Hypertension in Rats. B Bull Exp Biol Med 2004; 138(1): 103-105.

14. Bhat SA, Goel R, Shukla R, Hanif K. Platelet CD40L induces activation of astrocytes and microglia in hypertension. Brain Behav and Immun 2017; 59: 173189. 
15. Singh A, Kumar BS, Alam S, lqbal $H$, Shafiq $M$, Khan $F$, Negi AS, Hanif K, Chanda D. Diethyl-4,4'-dihydroxy-8,3'neolign-7,7'-dien-9,9'-dionate exhibits antihypertensive activity in rats through increase in intracellular cGMP level and blockade of calcium channels. Eur $J$ Pharmacol 2017; 799: 84-93.

16. Ashoor R, Yafawi R, Jessen B, Lu S. The Contribution of Lysosomotropism to Autophagy Perturbation. PloS one 2013; 8(11): e82481-e82481.

17. $\mathrm{Xu} Z$ Z, Klionsky DJ. Autophagy promotes cell motility by driving focal adhesion turnover. Autophagy 2016; 12(10): 1685-1686.

18. Kenific CM, Wittmann T, Debnath J. Autophagy in adhesion and migration. Cell Sci 2016; 129(20): 36853693.

19. Rajendran P, Rengarajan T, Thangavel J, Nishigaki Y, Sakthisekaran D, Sethi G, Nishigaki I. The Vascular Endothelium and Human Diseases. Int J Biol Sci 2013; 9(10): 1057-1069.
20. McCarthy CG, Wenceslau CF, Goulopoulou S, Baban B, Matsumoto T, Webb RC. Chloroquine Suppresses the Development of Hypertension in Spontaneously Hypertensive Rats. Am J Hypertens 2017; 30(2): 173181.

21. Lu D, Kassab GS. Role of shear stress and stretch in vascular mechanobiology. J $R$ Soc Interface 2011; 8(63): 1379-1385.

22. Lin L, Zou Y. Angiotensin II type 1 receptor mediated cardiomyocyte autophagy induced by mechanical stress through P38 MAPK. Heart 2012; 98(Suppl 2): E31-E31.

23. King JS, Veltman DM, Insall $R H$. The induction of autophagy by mechanical stress. Autophagy 2011; 7(12): 1490-1499.

24. Renna NF, de las Heras N, Miatello RM. Pathophysiology of Vascular Remodeling in Hypertension. Int $J$ Hypertens 2013; 7: 808353-808353. 